\title{
CONSIDERAÇÕES ACERCA DAS RODAS DE LEITURA USADAS COMO ATIVIDADES DE ENSINO
}

\author{
Consideraciones acerca de las ruedas de lectura utilizadas como \\ actividades didácticas
}

\author{
Diogo Fernando dos SANTOS \\ Universidade de Taubaté \\ diogofernandodossantos@gmail.com \\ https://orcid.org/0000-0001-8930-2061
}

\begin{abstract}
RESUMO: Este artigo é parte de uma dissertação de mestrado que discutiu as rodas de leitura realizadas com alunos do $5^{\circ}$ ano do Ensino Fundamental I de uma escola pública do interior paulista. O objetivo é discutir contribuições sobre momentos literários organizados pelo professor nas aulas. O trabalho baseou-se nas contribuições de Solé (1998), Lerner (2002) e Vigotsky (2009, 2010a, 2010b, 2014). O corpus apresenta abordagem qualitativa com recortes de protocolos de sala de aula. Os resultados mostraram que as reações dos alunos motivaram aprofundar as leituras com o intuito de que pudessem se manifestar, evidenciando opiniões e entendimento sobre o lido.
\end{abstract} PALAVRAS-CHAVE: Ensino Fundamental I; Roda de leitura; Formação de leitores.

RESUMEN: Este artículo es parte de una disertación de maestría que discutió sobre las ruedas de lectura realizadas con alumnos de $5^{\circ}$ año de Enseñanza Primaria de una escuela pública del interior del estado de São Paulo (Brasil). El objetivo es discutir contribuciones sobre momentos literarios organizados por el profesor en las clases. El trabajo estuvo basado en las contribuciones de Solé (1998), Lerner (2002) y Vigotsky (2009, 2010a, 2010b, 2014). El corpus presenta un abordaje cualitativo con recortes de protocolos del aula. Los resultados mostraran que las reacciones de los alumnos motivaron profundizar a las lecturas con el intuito de que se pudiesen manifestar, evidenciando opiniones y entendimiento sobre lo leído. PALABRAS CLAVE: Enseñanza Primaria; Rueda de lectura; Formación de lectores. 


\section{INTRODUÇÃO}

Nossa intenção é discutir as contribuições feitas a respeito das rodas literárias ${ }^{1}$ que organizamos no início das aulas, quando líamos para os alunos. Os registros feitos no diário de bordo contribuíram para uma análise mais apurada acerca dos efeitos positivos ocorridos ao longo de quatro semanas de experimentação.

O objetivo dessa experimentação foi observar as reações dos alunos e ver possíveis mudanças comportamentais que nos levariam a dar sequência a um projeto de escrita que pretendíamos desenvolver em sala de aula. Esse projeto partiu de uma necessidade verificada no início do ano letivo, quando passamos observar as produções escritas desses alunos e constatamos que os textos produzidos por eles a respeito de um gênero autobiográfico eram desprovidos de coerência e coesão, além de apresentarem excessivos erros ortográficos e precário uso de pontuação. A ideia inicial do projeto seria a leitura de textos bem escritos, nos quais os alunos pudessem analisar os aspectos linguísticos e notacionais utilizados por Clarice Lispector e Sylvia Orthof. Dessa forma, os alunos conscientes do uso desses recursos melhorariam as suas produções escritas.

Para a construção desse projeto com justificativa no ensino de procedimentos leitores e escritores, avaliamos que seria importante que houvesse uma preparação dos alunos para a imersão nessa modalidade organizativa (LERNER, 2002), a qual duraria em torno de três meses. No entanto, percebemos que apenas identificar as inadequações nas produções escritas e planejar e registrar uma sequência didática que trabalharia determinados conteúdos clássicos, não seriam condições suficientes. Havia outros procedimentos importantes a serem ensinados antes de se iniciar o projeto. Envolver os alunos afetivamente em leitura, preparar o espaço e ensinar a ouvir foram situações determinantes nessa preparação.

Por essa razão, nosso objetivo neste trabalho é apresentar os registros colhidos nessas rodas de leitura e avaliar as consequências dessa preparação. Assim, é possível ir além do que consta na dissertação e relatar com mais propriedade o sentido que as rodas de leitura tiveram para os alunos ao enfrentarem suas dificuldades para trabalhar com as obras vindouras de duas renomadas escritoras.

Nosso ensejo vai ao encontro de uma afirmação feita por Solé (1998, p. 72):

\footnotetext{
${ }^{1}$ Este artigo é parte de um trabalho de dissertação de mestrado em que se priorizou discutir as rodas de leitura realizadas com alunos do $5^{\circ}$ do Ensino Fundamental I de uma escola pública do interior paulista.
}

Revista X, v. 16, n. 3, p. 847-860, 2021. 
Formar leitores autônomos também significa formar leitores capazes de aprender a partir dos textos. Para isso, quem lê deve ser capaz de interrogar-se sobre sua própria compreensão, estabelecer relações entre o que lê e o que faz parte do seu acervo pessoal, questionar seu conhecimento e modificá-lo, estabelecer generalizações que permitam transferir o que foi aprendido para outros contextos diferentes.

No entanto, os alunos não se encontravam com essas habilidades descritas pela autora. Dessa forma, concluímos que não seria viável iniciar as rodas de leitura com obras de Clarice Lispector e de Sylvia Orthof ${ }^{2}$, tendo como objetivo ler para aprender. Assim, seria preciso envolver e motivar os alunos, criar uma conexão afetiva nas relações, tornar o lido algo que fizesse sentido para eles. "A motivação está intimamente relacionada às relações afetivas que os alunos possam ir estabelecendo com a língua escrita." (SOLÉ, 1998, p. 92).

Empreenderemos nosso trabalho baseando-nos, principalmente, nas contribuições de Solé (1998) acerca das estratégias de leitura e formação de leitores; Lerner (2002) no que trata do papel da leitura e da escrita na escola; Vigotsky ${ }^{3}(2009,2010 a, 2010 b, 2014)$ acerca da formação de conceito, do processo de maturação das funções psicológicas superiores e da zona de desenvolvimento imediato. O corpus dessa pesquisa se pauta numa abordagem qualitativa que apresenta recortes de protocolos de sala de aula.

Iniciamos nossa discussão a respeito do processo de maturação das funções psicológicas superiores para, posteriormente, discorrermos sobre a leitura feita pelo professor.

\section{A IMPORTÂNCIA DO COLETIVO}

A escola é um local de socialização do conhecimento, porém, devemos refletir sobre qual conhecimento é transmitido pela escola. Qual seria de fato a concepção de conhecimento que baliza um currículo escolar e é transmitido didaticamente pelo professor? Para esse questionamento, pautamo-nos na Pedagogia Histórico-Crítica, a qual defende que, de acordo com Saviani (2013), o conhecimento transmitido pela

\footnotetext{
${ }^{2}$ As obras infantis de Clarice Lispector escolhidas para esse projeto foram: Quase de verdade (1999); A vida intima de Laura (1999); A mulher que matou os peixes (1993); O mistério do coelho pensante (1985) e uma única obra infantil de Sylvia Orthof - Os bichos que tive (2007).

${ }^{3}$ Ao longo do texto, é usada a grafia do nome do autor dessa forma "Vigotsky". No entanto, de acordo com as obras consultadas, também foi assinalada a grafia "Vigotski" nas citações e na referência.
} 
instituição escolar baseia-se na socialização de um saber sistematizado. Para o autor, o homem não nasce humano, a humanização é um produto histórico-cultural. Ela é

[...] produzida sobre a base da natureza biofísica. Consequentemente, o trabalho educativo é o ato de produzir, direta ou indiretamente, em cada indivíduo singular, a humanidade que é produzida histórica e coletivamente pelo conjunto de homens. (SAVIANI, 2003, p. 13).

Martins (2013) corrobora afirmando que a educação escolar contribui para o desenvolvimento psíquico dos indivíduos, permitindo ao homem se desenvolver em sua totalidade. Por essa razão, os conteúdos escolares estão intimamente ligados aos conteúdos universais, os quais foram elaborados na esteira cultural e científica ao longo da humanidade. Assim, de acordo com a autora, o trabalho produzido pelos homens são produtos de um trabalho imaterial e, por essa razão, cabe à educação escolar oportunizar condições para que os alunos se apropriem desses conhecimentos historicamente produzidos. Inferimos ser necessário ao professor dominar os conteúdos clássicos da área em que atua, sabendo fazer a transposição didática desses conteúdos, escolarizando-os para que o aluno compreenda. A nosso ver, entendemos que não adianta falar de inovação e tecnologia em sala de aula se não houver domínio sobre os conteúdos clássicos.

Nessa mesma direção, Vigotsky (2009) comenta que o desenvolvimento das funções psicológicas superiores acontece mediante o ensino. É por meio da educação escolar que o indivíduo transformará os conhecimentos espontâneos, cuja definição se resume no processo de experiência pessoal da criança, em conhecimentos científicos.

O curso do desenvolvimento do conceito científico nas ciências sociais transcorre sob as condições do processo educacional, que constitui uma forma original de colaboração sistemática entre o pedagogo e a criança, colaboração essa em cujo processo ocorre o amadurecimento das funções psicológicas superiores da criança com o auxílio e a participação do adulto. (VIGOTSKY, 2009, p. 244).

$\mathrm{O}$ ato de colaborar para a ascensão do amadurecimento das funções psicológicas superiores da criança não pode ser reduzido à transmissão mecânica de conceitos, à mera memorização que leva o aluno a repetições desnecessárias e equivocadas, tornando a apreensão do conhecimento vivo em infrutíferos esquemas verbais mortos e vazios (VIGOTSKY, 2009). O desenvolvimento de conceitos científicos requer "o desenvolvimento de toda uma série de funções como a atenção arbitrária, a memória lógica, a abstração, a comparação e a discriminação, e todos esses processos psicológicos 
sumamente complexos." (VIGOTSKY, 2009, p. 246). Aprender o significado de uma palavra é o limiar de uma longa jornada de aprendizado para a criança. No início a palavra é apenas uma generalização rudimentar, conforme a criança se desenvolve, outras generalizações vão sendo formadas em um grau mais elevado, assim resulta na real formação dos conceitos.

É durante o processo de maturação que o olhar atento do educador se intensifica para ensinar o que de fato a criança ainda não domina. Vigotsky (2009) coloca em tela que o surgimento de conceitos científicos ocorre mediante intervenções feitas pelo educador que impulsionam a criança a elaborar o seu próprio pensamento.

A discussão desse assunto é pertinente, pois não adiantaria para nós, por meio de uma avaliação inicial, apenas constatar as dificuldades dos alunos e posteriormente aplicar uma série de atividades com a intenção de obter a reversão desse quadro. A proposição era constatar as falhas encontradas nas produções escritas dos alunos e, por meio das rodas de leitura, sensibilizá-los, criando condições para o desenvolvimento da linguagem escrita. A necessidade estabelecida naquela ocasião era a conexão que seria feita entre professor e alunos. O caminho que tomamos para estabelecer vínculos afetivos com os discentes foi semear valores acerca do ensino da leitura. De acordo com Silva e Abud (2012), uma das alternativas para a compreensão de valores que orientam as ações humanas pode ser feita por meio do trabalho com histórias. "Podemos acrescentar que uma história defende sempre um ponto de vista, e subjacente a este se encontram os valores que o anteparam." (SILVA; ABUD, 2012, p. 63).

A consciência de todo trabalho que seria desenvolvido pairava na necessidade de entendermos os alunos e com a ajuda deles descobrirmos caminhos para o ensino e a aprendizagem.

\section{A AFETIVIDADE FOI A CHAVE-MESTRA}

Tornar o homem mais sensível e consciente de sua moralidade humana pode ser possível por meio da literatura, segundo Candido (1995). Para o autor, a literatura torna-se um direito comum a todos os homens, não está apenas destinada aos intelectuais e a uma classe econômica abastada. Assim, da mesma forma que ao homem lhe são concedidas as condições essenciais para a sua sobrevivência com direito ao acesso à moradia, à instrução, à saúde, ao vestuário, ao lazer, à liberdade; a literatura também é um bem comum e essencial para sua formação humana. Um povo edifica-se mediante o contato com suas riquezas culturais. O espírito do homem é preenchido por sonhos e fantasias que lhes permitem evoluir e a literatura é a porta de entrada para essa evolução. 
Por conseguinte, a literatura é toda expressão cultural e artística dentro de qualquer seguimento da sociedade, como teatro, poesia, música, arte, ela não se destina apenas aos clássicos escritos.

Assim, a literatura consegue "[...] dar forma aos sentimentos e à visão do mundo ela nos organiza, nos liberta do caos e portanto nos humaniza" (CANDIDO, 1995, p. 256). Ao mesmo tempo a literatura é direito de todos por se tratar de "[...] um instrumento consciente do desmascaramento, pelo fato de focalizar as situações de restrição dos diretos, ou de negação deles, como a miséria, a servidão, a mutilação espiritual" (CANDIDO, 1995, p. 256).

Para tanto, a escola é um espaço para a sensibilização e a humanização do homem. Segundo Vigotski (2014, p. 61), “a verdadeira educação consiste em despertar na criança aquilo que ela já tem em si, ajudá-la a desenvolvê-lo e orientar seu desenvolvimento em determinada direção." Dessa maneira, a importância de ensinar os conteúdos clássicos para os alunos é um fator determinante para o processo de humanização. Portanto, ler e escrever fazem parte desse ensino dos conteúdos clássicos. Ajudar o aluno a produzir seus textos e a desenvolver sua criatividade por meio de estímulos são condições inerentes ao ensino de boas práticas pedagógicas.

A criação literária poder ser estimulada e orientada e deve ser avaliada
a partir de seu significado objetivo para o desenvolvimento e educação
da criança. Tal como ajudamos as crianças a organizar os seus jogos,
escolhemos e orientamos a sua atividade lúdica, também podemos
estimular e orientar a sua habilidade artística. (VIGOTSKI, 2014, p. 80).

Estimular para a criação literária, segundo o autor, é permitir que o aluno desenvolva a imaginação criativa que lhe dará uma nova direção à sua fantasia, perpetuando-se ao longo de sua vida.

O seu sentido reside no fato de ela aprofundar, ampliar e aperfeiçoar a vida emocional da criança que, pela primeira vez, é despertada e dirigida para uma ação séria; por último, seu significado reside no fato de que permite à criança, ao exercitar seus impulsos e hábitos criativos, dominar a linguagem humana, a ferramenta mais sutil e complexa para formular e transmitir os pensamentos humanos, seus sentimentos, o mundo interior do homem. (VIGOTSKI, 2014, p.84-85).

Tal linguagem está intrinsecamente ligada às emoções experienciadas pelo indivíduo. Segundo Silva e Abud (2012), as experiências traçam a forma de ser de cada um. Sua bagagem de conhecimento cultural, cognitivo e emocional vai, ao longo 
de sua jornada humana, sendo modificada por aquisições de novos conhecimentos e experiências vivenciadas. As autoras, pautadas em Vigotski, comentam que a introdução da afetividade na aprendizagem é um fator determinante para a construção do conhecimento. Para Vigotski (2010a), a vivência é uma condição valiosa pois há nela elementos determinantes que influenciam o meio no desenvolvimento psicológico do indivíduo, abarcando também o desenvolvimento de sua personalidade.

\begin{abstract}
A vivência de uma situação qualquer, a vivência de um componente qualquer do meio determina qual influência essa situação ou esse meio exercerá na criança. Dessa forma, não é esse ou aquele elemento tomado independentemente da criança, mas, sim, o elemento interpretado pela vivência da criança que pode determinar sua influência no decorrer de seu desenvolvimento futuro. (VIGOTSKI, 2010a, p.683-684).
\end{abstract}

Assim, de acordo com Silva e Abud (2012, p. 65), "o desenvolvimento de uma criança depende da maneira como ela vivencia uma situação no ambiente, isto é, como ela se torna consciente daquele evento, como o interpreta e como emocionalmente se relaciona com ele."

As rodas de leitura tiveram o objetivo de sensibilizar o olhar da criança para a leitura, contribuir para o seu amadurecimento emocional e cognitivo. Não foi o simples fato de ler para os alunos todos os dias que os sensibilizaram, foi o vínculo afetivo criado na relação professor-aluno que nos proporcionou dar continuidade ao projeto de leitura.

\title{
COMO TUDO COMECYU: AS RODAS DE LEITURA
}

Primeiramente, houve um olhar atento do professor para entender quais seriam as boas intervenções que poderiam ser feitas naquele espaço de socialização do conhecimento. Ler para fruição não era uma situação comum na rotina daqueles alunos. Um dos primeiros questionamentos feitos por esse educador foi descobrir quem lia livros de literatura. Apenas uma única aluna, dos vinte presentes naquele momento, sinalizou que gostava de ler, porque a mãe lia muito em casa e que fazia parte de sua rotina ir à biblioteca municipal emprestar livros. Outros comentaram que liam os livros da caixa de leitura disponibilizada pela professora do ano anterior. Na caixa, constavam gibis, revistas e livros de leitura com pouca escrita. De acordo com eles, os livros com muito texto eram algo cansativo de ler. Liam quase sempre no final da aula em silêncio. A leitura silenciosa era uma prática corriqueira. Não havia um rodízio constante desses livros. 
Fizemos um questionamento a respeito desse momento de leitura silenciosa:
$P^{4}$ - Quando vocês pegavam o livro ou a revista para ler, liam tudo?
A1 - Nem sempre, quando o livro era grande eu via só as imagens. Sempre gostei de livros com imagens, é mais rápido de ler.
$P$ - Mas nunca pensou em ler esse livro grande um pouquinho a cada dia?
Al - Ah, a professora falava... (pausa) mas eu também queria ler outras coisas...
$P$ - Em algum momento vocês chegaram a conversar sobre os livros lidos?
A2 - Só quando a professora lia as histórias do livro de português. Daí a gente conversa sobre a história.

Para Lerner (2002), inserir o aluno na cultura do escrito é o grande desafio da escola. Isso diz respeito à apropriação de um conhecimento cultural que envolve "o exercício de diversas operações com os textos e a colocação em ação de conhecimentos sobre as relações entre os textos; entre eles e seus autores; entre os próprios autores; entre os autores; os textos e seus contextos..." (LERNER, 2002, p. 17). Estávamos diante de leitores que precisavam ser inseridos nessa cultura. No entanto, para que os alunos chegassem a uma autonomia leitora precisariam ser estimulados a entender de fato o porquê de ler ser importante, sem se fazer um discurso enfadonho sobre a importância da leitura. De acordo com a autora (2002, p. 17-18),

\begin{abstract}
o necessário é fazer da escola uma comunidade de leitores que recorrem aos textos buscando resposta para os problemas que necessitam resolver, tratando de encontrar informação para compreender melhor algum aspecto do mundo que é o objeto de suas preocupações, buscando argumentos para defender uma posição com a qual estão comprometidos, ou para rebater outra que consideram perigosa ou injusta, desejando conhecer outros modos de vida, identificar-se com outros autores e personagens ou se diferenciar deles, viver outras aventuras, inteirar-se de outras histórias, descobrir outras formas de utilizar a linguagem para criar novos sentidos.
\end{abstract}

Assim, com a ideia de construirmos com aquele $5^{\circ}$ ano uma comunidade de leitores ativos, propusemos que fizessem uma roda no fundo da sala e apresentamos o seguinte comentário: Todos os dias, antes de iniciarmos as atividades, gostaria de fazer uma roda de leitura no fundo da sala. Quero ler para vocês algumas histórias que conheço e que são bem interessantes.

\footnotetext{
${ }^{4}$ Definimos (P) para professor e (A) para alunos.

Revista X, v. 16, n. 3, p. 847-860, 2021.
} 
Anotamos as reações de alguns alunos:

Quadro 1: Anunciação das rodas de leitura.

\begin{tabular}{|c|c|}
\hline Aluno 1 & O senhor vai ler pra gente...? A gente já sabe ler... \\
\hline Aluno 2 & A gente vai ler também a história no livro da sala? \\
\hline Aluno 3 & $\begin{array}{r}\text { No ano passado, a professora Fernanda }{ }^{5} \text { lia para gente, mas depois a gente } \\
\text { tinha que fazer trabalho. O senhor vai dar trabalho pra gente? }\end{array}$ \\
\hline Aluno 4 & Lá em Belém a gente fazia coisas de escola... ler, a gente não lia não... \\
\hline
\end{tabular}

Fonte: Elaboração própria.

Explicamos aos alunos que sempre no início do dia uma história seria lida. Sem nos aprisionarmos a um gênero específico, comentamos que as leituras iriam desde contos curtos, poemas, reportagens até anedotas. Não haveria perguntas no final, nem exercícios para serem respondidos no caderno. Se a leitura não agradasse, poderiam comentar ou não; e se gostassem poderiam se expressar também. Seria um momento para começar o dia de forma diferente do que estavam acostumados.

A construção de uma comunidade leitora não seria um trabalho fácil de ser implantado, mas não seria algo impossível, o que precisávamos era conhecer o grupo de alunos, entender suas necessidades, conhecer suas potencialidades e limitações. Concordamos com Lerner (2002) quando anuncia que as reformas educativas, as quais geram mudanças profundas, tropeçam em resistências imensuráveis. Segundo a autora, ainda existe um abismo entre a prática escolar da prática social de leitura e escrita. "A língua escrita, criada para representar e comunicar significados, aparece em geral na escola fragmentada em pedacinhos não-significativos." (LERNER, 2002, p. 33). A pergunta que fizemos para nós mesmos ao longo dos questionamentos dos alunos foi: “Onde está o ler para sentir, emocionar e fantasiar sobre o que é lido?" Estávamos diante de uma mudança de paradigmas, de levar a leitura como um princípio humanizador, visto que por meio dela o aluno poderia manifestar suas emoções, ampliar sua visão de mundo e expandir seus conhecimentos (CANDIDO, 1995).

\footnotetext{
${ }^{5}$ Nome fictício. 
Para essas rodas de leitura, foi preciso criar alguns procedimentos sobre:

a. Textos: seriam escolhidos pequenos poemas, fábulas e minicontos, reportagens, anedotas. Em um segundo momento, contos infantis.

b. Tempo: começaríamos com cinco minutos, aumentando gradativamente ao longo das semanas o tempo de leitura.

c. Encerramento: a leitura não seria discutida, apenas se algum aluno quisesse se manifestar, então, seria ouvido.

d. Organização da sala: em roda, sentados no chão.

e. Intervenções do professor: perguntas sobre o título, apresentação do autor, ilustrador, editora, bem como perguntas durante a história com a intenção de criar um clímax maior no texto lido.

O quadro abaixo mostra o desconforto e as dificuldades que encontramos nas duas primeiras semanas de leitura realizada diariamente e as mudanças no sentido de envolvimento dos alunos nas duas últimas semanas do mesmo mês.

Quadro 2: O desafio de introduzir a roda de leitura.

\begin{tabular}{|c|c|}
\hline as & Is \\
\hline $\begin{array}{l}\text { - Resistência de alguns alunos para } \\
\text { sentar no chão; } \\
\text { - Conversas constantes durante a } \\
\text { leitura feita pelo professor; } \\
\text { - } \quad \text { Leitura interrompida por alunos } \\
\text { com pedidos para ir ao banheiro } \\
\text { ou para beber água; } \\
\text { - Brincadeiras entre os meninos, } \\
\text { um deles acreditava que seria o } \\
\text { momento para recreação e, por } \\
\text { isso, começou a levar carrinhos } \\
\text { para as rodas de leitura. }\end{array}$ & $\begin{array}{l}\text { - As conversas diminuíram; } \\
\text { - O professor já não era mais interrompido } \\
\text { (começaram a entender os combinados para } \\
\text { aquele momento); } \\
\text { - } \text { Algumas alunas começaram a esboçar pequenos } \\
\text { comentários após a leitura; } \\
\text { - Os meninos ainda demonstravam resistência, } \\
\text { mas já não atrapalhavam tanto como no início. } \\
\text { No final da terceira semana, algumas alunas já } \\
\text { começaram a organizar o espaço no fundo da } \\
\text { sala, antes mesmo do professor pedir; } \\
\text { Respondiam às perguntas feitas pelo professor } \\
\text { sobre o título da obra ou qualquer outra feita } \\
\text { durante a história. }\end{array}$ \\
\hline
\end{tabular}

Fonte: Elaboração própria. 
Aprender a ouvir foi uma condição difícil para alguns alunos. Era notável a estranheza no olhar de alguns a respeito de tudo que estávamos fazendo, pois não entendiam o sentido de tudo aquilo. Ao longo da semana, conforme aumentávamos o tempo de leitura, aumentava também a nossa preparação para esse momento. Tínhamos que estudar o texto antes para buscar a entonação certa para passar por meio da leitura todo o sentimento das personagens. Criamos estratégias de leitura, as quais são discutidas por Solé (1998), como as de antecipação da história analisando apenas o título apresentado e depois a verificação das hipóteses levantadas, uma forma de fazer previsões sobre o texto. Formulamos perguntas sobre a história lida e esclarecemos dúvidas surgidas durante as narrativas; algumas vezes, resumíamos as principais ideias do texto lido. Utilizamo-nos desses artifícios para envolver os alunos a cada dia que passava. Parávamos a leitura no ápice da história e lançávamos uma pergunta a todos. Rimo das trapalhadas das personagens e nos emocionamos com outras. As narrativas para emocionar contagiaram boa parte das meninas. Percebemos que a grande maioria delas era sentimental, sensível e, por isso, levamos para a leitura em sala de aula os contos Raposa, de Margaret Wild (2005); A sereiazinha e A pequena vendedora de fósforos de Hans Christian Andersen (1995).

Vejamos alguns comentários feitos pelos alunos na leitura dos contos de Andersen:

Quadro 3: Comentários após a leitura.

\begin{tabular}{|c|c|}
\hline Aluno 1 & $\begin{array}{c}\text { Eu já li a pequena sereia... mas você contou diferente, } \\
\text { parece uma outra história... }\end{array}$ \\
\hline Aluno 2 & Ai, da um negócio na gente saber que a menina morreu de frio... \\
\hline Aluno 3 & $\begin{array}{r}\text { A sereiazinha morreu de amor... ela não queria matar o príncipe. Achei bonito } \\
\text { o jeito como o autor escreveu... }\end{array}$ \\
\hline Aluno 4 & A sereiazinha foi a melhor história que o senhor já leu pra gente. \\
\hline Aluno 5 & $\begin{array}{c}\text { Eu gostei mais da menina da caixa de fósforo, lê de novo pra gente, } \\
\text { na outra semana? }\end{array}$ \\
\hline
\end{tabular}

Fonte: Elaboração própria.

Foi um trabalho paulatino, a cada leitura feita introduzia-se uma nova informação: sobre autor da história, ilustrador, editora, ficha catalográfica, capa, contracapa, capa de rosto, quarta capa, numeração, sumário, prefácio e miolo do livro. Era relevante apresentar essas informações de forma contextualizada para que os alunos vivenciassem 
os assuntos a serem estudados. Acreditamos que, antes de introduzir as explicações sobre o assunto a ser estudado, o docente deve fazer não só com que os alunos pensem e assimilem determinado conteúdo, como também os vivenciem emocionalmente (VIGOTSKY, 2010b). Desse modo, Vigotsky (2010b) também salienta que o professor deve atentar-se em relacionar um novo conhecimento com emoção, senão o saber tornase alheio à experiência do aluno. Por isso, o autor afirma: "O momento da emoção e do interesse deve necessariamente servir de ponto de partida a qualquer trabalho educativo." (VIGOTSKY, 2010b, p. 145).

\section{CONSIDERAÇÕES FINAIS}

Em síntese, o nosso objetivo era provocar nesses alunos o interesse e o gosto pela leitura. Iniciamos com as rodas de leitura cujo intuito era ler diariamente para esses estudantes focando a fruição e a estética desses textos. Tínhamos o desafio de criar uma comunidade de leitores ativos. Como vimos, de acordo com Solé (1998), essa comunidade leitora levaria a uma autonomia cujo ideal seria o questionamento sobre o lido, interrogando sua própria compreensão, ampliando seus conhecimentos e, ao mesmo tempo, dando ao aluno condições para modificá-los.

Respeitamos o tempo e o entendimento de cada discente para a proposta apresentada. No entanto, sabíamos que havia a necessidade de criar um procedimento de trabalho para tal momento compartilhado. Tínhamos um objetivo didático pontuado, dessa forma, precisávamos registrar as reações dos alunos e os avanços pedagógicos feitos ao longo das semanas. Não os sensibilizamos por meio de aconselhamentos doutrinários ou moralistas, sensibilizamos boa parte dos ouvintes por estabelecer conexão entre o lido e o falado ${ }^{6}$; entre o meio e as vivências de cada aluno.

As reações e emoções demonstradas por alguns nos motivaram a aprofundar as leituras feitas com o intuito de que vários pudessem se manifestar, evidenciando suas opiniões e entendimento sobre o lido. Quando, no final da terceira semana, algumas alunas começaram a organizar o fundo da sala de aula para o momento literário, consideramos isso como um ponto primordial de mudança de comportamento. A demonstração de interesse vinha por meio desse ato. Os interessados passaram a cobrar daqueles menos envolvidos com a proposta. Então, o interesse de alguns contagiou a grande maioria.

\footnotetext{
${ }^{6}$ No caso do termo falado, fazemos referência as nossas emoções despertadas que nos proporcionavam comentar durante a história lida.
} 
Portanto, emoção e interesse foram as peças de engrenagem para o envolvimento desses estudantes a uma proposta de leitura que tomaria, posteriormente, uma proporção maior.

\section{REFERÊNCIAS}

ANDERSEN, Hans Christian. A sereiazinha. In: ANDERSEN, Hans Christian. Histórias maravilhosas de Andersen. Tradução Heloisa Jahn. São Paulo: Companhia das Letrinhas, 1995. p. 62-91.

ANDERSEN, Hans Christian. A pequena vendedora de fósforos. In: ANDERSEN, Hans Christian. Histórias maravilhosas de Andersen. Tradução Heloisa Jahn. São Paulo: Companhia das Letrinhas, 1995. p. 102-105.

CANDIDO, Antonio. O direito à literatura. In: CANDIDO, Antonio. Vários escritos. 3. ed. São Paulo: Duas Cidades, 1995. p. 235-263.

LERNER, D. Ler e escrever na escola: o real, o possível e o necessário. Porto Alegre: Artmed, 2002.

MARTINS, Lígia Marcia. Os fundamentos psicológicos da Pedagogia Histórico-Crítica e os fundamentos pedagógicos da Psicologia Histórico-Cultural. Germinal: Marxismo e Educação em Debate, Salvador, v. 5, n. 2, p. 130-143, dez. 2013.

SAVIANI, Dermeval. Pedagogia Histórico-crítica: primeiras aproximações. 11. ed. Campinas, SP: Autores Associados, 2013.

SILVA, Elisabeth Ramos; ABUD, Maria José Milharezi. A identificação de valores em recordações docentes de histórias infantis. Revista Intercâmbio, v. XXVI, p. 61-79, 2012. São Paulo: LAEL/PUCSP. ISSN 2237-759X.

SOLÉ, Isabel. Estratégias de leitura. 6. ed. Tradução Cláudia Schilling. Porto Alegre: Artmed, 1998.

VIGOTSKI, Lev Semenovich. Quarta aula: a questão do meio na pedologia. Tradução de Márcia Peleggi Vinha. Psicologia USP, São Paulo, 2010a, p. 681-701.

VIGOTSKI, Lev Semenovich. Imaginação e criatividade na infância. Tradução de João Pedro Fróis. São Paulo: Martins Fontes, 2014.

VIGOTSKY, Lev Semenovich. A construção do pensamento e da linguagem. Tradução de Paulo Bezerra. 2. ed. São Paulo: Martins Fontes, 2009. 
VIGOTSKY, Lev Semenovich. Psicologia pedagógica. Tradução Paulo Bezerra. 3. ed. São Paulo: Martins Fontes, 2010b.

WILD, M. Raposa. Tradução Gilda Aquino. São Paulo: Brinque-Book, 2005.

Recebido em: 11 fev. 2021. Aceito em: 21 abr. 2021. 